\title{
Appearance of fetal pain could be associated with maturation of the mesodiencephalic structures
}

This article was published in the following Dove Press journal:

Journal of Pain Research

II November 2016

Number of times this article has been viewed

\author{
Slobodan Sekulic' \\ Ksenija Gebauer-Bukurov' \\ Milan Cvijanovic' \\ Aleksandar Kopitovic' \\ Djordje Ilic $^{2}$ \\ Djordje Petrovic ${ }^{2}$ \\ Ivan Capo ${ }^{3}$ \\ Ivana Pericin-Starcevic ${ }^{4}$ \\ Oliver Christ ${ }^{5}$ \\ Anastasia Topalidou ${ }^{6}$ \\ 'Department of Neurology, Faculty \\ of Medicine Novi Sad, University of \\ Novi Sad, ${ }^{2}$ Department of Obstetrics \\ and Gynecology, Faculty of Medicine \\ Novi Sad, University of Novi Sad, \\ ${ }^{3}$ Department of Histology and \\ Embryology, Faculty of Medicine \\ Novi Sad, University of Novi Sad, \\ ${ }^{4}$ Department of Developmental \\ Neurology and Epilepsy, Institute \\ for Child and Youth Health Care of \\ Vojvodina, Faculty of Medicine Novi \\ Sad, University of Novi Sad, Novi Sad, \\ Serbia; ${ }^{5}$ School of Applied Psychology, \\ Institute Humans in Complex Systems, \\ Olten, Switzerland; ${ }^{\circ}$ Department \\ of Orthopaedics and Traumatology, \\ University Hospital of Heraklion, \\ Faculty of Medicine, University of \\ Crete, Heraklion, Greece
}

Correspondence: Slobodan Sekulic Department of Neurology, Clinical Center of Vojvodina, Hajduk Veljkova I-7, 21000 Novi Sad, Serbia

Tel +381643886715

Email slobodan.sekulic@mf.uns.ac.rs

\begin{abstract}
Fetal pain remains a controversial subject both in terms of recognizing its existence and the time-frame within which it appears. This article investigates the hypothesis that pain perception during development is not related to any determined structures of the central nervous system (CNS), on the contrary, the process of perception could be made with any structure satisfying conditions that the perception of pain is the organization, identification, and interpretation of sensory information in order to represent and understand the environment. According to this definition, chronic decerebrate and decorticate experimental animals, anencephalic, and hydranencephalic patients demonstrate that the basic, most general, appropriate interaction with the environment can be achieved with a functional mesodiencephalon (brain stem, and diencephalon) as the hierarchically highest structure of the CNS during development. In intact fetuses, this structure shows signs of sufficient maturation starting from the 15 th week of gestation. Bearing in mind the dominant role of the reticular formation of the brain stem, which is marked by a wide divergence of afferent information, a sense of pain transmitted through it is diffuse and can dominate the overall perception of the fetus. The threshold for tactile stimuli is lower at earlier stages of gestation. The pain inhibition mechanisms are not sufficiently developed during intrauterine development, which is another factor that leads to increased intensity of pain in the fetus. As a conclusion it could be proposed that the fetus is exposed to rudimentary painful stimuli starting from the $15^{\text {th }}$ gestation week and that it is extremely sensitive to painful stimuli.
\end{abstract}

Keywords: pain, fetus, perception, brain stem, thalamus

\section{Introduction}

While it is absolutely clear to the subject suffering pain just how much they are exposed to suffering as a result of noxious substances, there is a large difference in the opinions of others about how much pain the subject is exposed to, and whether the subject is experiencing pain at all. The differences in attitudes towards what structures of the central nervous system (CNS) are necessary for the patient to be experiencing pain become more significant when the necessity for the introduction of analgesic therapy is considered. ${ }^{1}$ This issue is particularly prominent in patients, such as those with brain damage, who cannot describe the pain through any form of communication. Fetal pain, which is the topic of this paper, is a special problem.

According to the International Association for the Study of Pain (IASP), pain is an unpleasant sensory and emotional experience associated with actual or potential tissue damage, or described in terms of such damage. ${ }^{2}$ The traditional standpoint is that the registering of a nociceptive stimulus with a sensory system and perceiving 
a nociceptive stimulus as painful are not the same process. ${ }^{3}$ Nociception includes registering noxious stimuli with specialized free nerve endings and transmitting information about it. Data provided with nociception are imperfect and incomplete for the CNS to make a direct copy for current events. Perception is the organization, identification, and interpretation of sensory information in order to represent and understand the environment. ${ }^{4}$

The classical view of the proper perception of pain is related to the processing of afferent nociceptive signals at the level of the cortex cerebri. The majority of current standpoints about fetal pain follow this concept. ${ }^{5-8}$ The perception of pain among adults encompasses the subject's consciousness and active cortex cerebri, which enables learning and activates memory and emotions in the process of pain processing. ${ }^{9}$ If the definition including the learning process and understating the cause-effect relationship is applied, it would mean that the infant would become aware of pain between the second and fourth week of postnatal life. ${ }^{5}$ Mellor et al completely dismiss the notion that the fetus feels pain during pregnancy. ${ }^{3}$ They believe that during intrauterine development the fetus is exposed to a combined neuroinhibitory action: 1) of an electroencephalogram (EEG) suppressor and sleep inducing agent (adenosine); 2) two neurosteroidal anesthetics (allopregnanolone, pregnanolone); and 3) a potent sleep-inducing hormone, prostaglandin D2 of endogenous origin or produced by the placenta. They believe that pain occurs immediately after birth. ${ }^{3}$ It should be noted that serum concentrations of adenosine are higher in preeclamptic mothers than in fetuses, but this does not provoke analgesia in mothers. ${ }^{10} \mathrm{At}$ the end of pregnancy, serum concentrations of progesterone are almost the same in fetuses $(822 \mathrm{nmol} / \mathrm{L})$ and mothers $(783 \mathrm{nmol} / \mathrm{L})$, again without analgesia in mothers. ${ }^{11}$ Pregnanolone is used as an anesthetic in experimental research with plasma concentrations ten to twenty times higher than in fetuses or pregnant females. ${ }^{12}$ Based on EEG analysis, Burgess and Tawia concluded that a fetus becomes conscious at about 30 to 35 weeks gestation and consequently feels pain in this period. ${ }^{13}$ Based on behavioral reactions to noxious stimulation, comparable to the adult or older child, Rogers concluded that the fetus feels pain as early as the 26th week of gestation. ${ }^{14}$ Derbyshire concludes, based on the necessity of cortex cerebri activity in processing pain perception, that the earliest period when the fetus can feel pain is the $23 \mathrm{rd}$ gestation week. That is the week when thalamic projections, which can transmit information about nociception to the cortical plate, are formed. ${ }^{5}$ The maturity of the thalamus and associated subcortical structures with proper thalamocortical connections at the 20th gestation week accompanied by a coordinating electroencephalogram rhythm, provide the possibility for the fetus to experience something approximating "pain". ${ }^{6}$ Studies have shown that hormones which represent fetal hypothalamic-pituitary-adrenal stress responses (cortisol, noradrenaline, beta-endorphin) increased significantly in the fetal plasma as a response to placing a needle in the intrahepatic vein reached by piercing the fetus's abdominal wall. Fetal beta-endorphin and noradrenalin responses were apparent from the 18th gestation week, whereas fetal cortisol responses were apparent from 20th gestation week. ${ }^{15,16}$ Glover and Fisk also take into account the activity of cortex cerebri in pain processing and consider that the 16th gestation week is the earliest possible period for the fetus to feel pain. ${ }^{7}$ The 16 th week sees the first contact of subplate zone with outer fibers which belong to the group of monoamine fibers and originate at the brain stem. ${ }^{8}$ The subplate zone is a temporary formation of the future mature cortex cerebri.

Some clinical data about adult human patients suggested that ablation as well as stimulation of the primary somatosensory cortex does not alter pain perception, whereas thalamic ablation stimulation does. ${ }^{17}$ This study shows that the cortex cerebri does not have to play a prominent role in the process of pain perception. Lesions of the cortex cerebri, no matter how extensive they are, are not associated with a coma. On the other hand, lesions of the reticular activating system, which includes intralaminar thalamic neurons, lead to loss of consciousness. ${ }^{18,19}$ Moreover, studies with experimental animals suggest that the brain stem and thalamus play an important integrative role in the elaboration and control of adaptive and motivated behavior. ${ }^{20}$

The assessment of pain in experimental animals is based on their behavior. Chronic decerebrates, such as mesencephalic cats or rats, upon nociceptive stimulation, exhibit crying, fear and the escape response; they also express elements of rage behavior. ${ }^{20,21}$ Decerebrate kittens can develop many behavioral patterns closely parallel with that of normal animals. ${ }^{22}$ These experiments indicate that the brain stem could organize and execute species-typical behaviors and partly even meaningful patterns of behavior. ${ }^{20}$ Likewise, the earlier the decerebration is done in relation to the maturity of the individual, the higher the possibility of its compensation abilities to damage. It is also possible that, after decerebration, the development of these structures are unmasked from the influence of higher hierarchical structures, and that they indicate their own physiological development. ${ }^{20,23}$ Decorticated experimental animals, such as the rat, also have behavioral patterns that resemble those of intact animals. ${ }^{24,25}$ 
Decerebrate and decorticate experimental animals show oral habituation, habituation to auditory and vibrotactile stimuli, and even classical conditioning of the eye blink reflex. ${ }^{26-31}$ The possibility of habituation and classical conditioning at the level of the mesodiencephalon shows its capability for learned modifications of the reflexes. More importantly, classical conditioning is associative learning which provides a possibility to link two items through experience. Pain perception could result from a learned association between nociception and the evoked unpleasant emotion. All those necessary components are present at the level of the mesodiencephalon in decerebrate as well as in decorticate experimental animals, as was quoted in the previous text.

It is a characteristic of the nervous system that structures which are at hierarchically lower levels mature faster. Human newborns are born with a mature subcorticospinal system of the brain stem which plays a leading role in the behavior of the newborn. ${ }^{32}$ During maturation neural elements are not assembled like a computer, which can be turned on once the final component is included. When it comes to the fetus, it has to be taken into account that the developing neural elements may be immature, but they are not inactive ${ }^{33}$ the developing pain system has a signaling function during the maturation of the fetus. This system uses the existing neural structures at that moment. ${ }^{33}$ According to this, the perception of pain during development is not related to any determined structures of the CNS, on the contrary, the process of pain perception could be made with any structure satisfying the conditions that perception is the organization, identification and interpretation of sensory information in order to represent and understand the environment.

All these data could lead to the hypothesis that the early rudimentary form of the perception of pain in human species could be achieved only with mesodiencephalic structures during intrauterine development.

\section{Habituation, conditioned associative learning, and the brain stem in human species}

Among decerebralized patients, it is possible to bring about the habituation of cardiac responses to auditory or visual stimuli. Furthermore, two paired stimuli result in the appearance of a marked cardiac orienting response to the unpredictable omission of the second stimulus, proving the development of simple conditioned associative learning. ${ }^{34}$ Habituation and conditioned associative learning at the level of the mesencephalon in adult patients show that during intrauterine development the mesencephalon has possibility not only for reflexive reaction, but its reaction could be based on rudimentary learning.

Fetuses start to respond to vibroacoustic stimulation from the 23 rd to the 24th gestational week. By the 30 th week of gestation, all fetuses respond. ${ }^{35}$ The blink-startle response appears from the 24th to the 25th week of gestation and is consistently present after the 28 th gestational week. ${ }^{36}$ The possibility of the modulation of responses, i.e. habituation, depends on the level of maturity of the sensory modalities involved in their registration. Registration of tactile stimuli appears at the 7 th gestation week while auditory brainstem responses appear at the 26th gestation week..$^{37,38}$ There are no published studies on habituation or classical conditioning with tactile stimuli in human fetuses.

An identical ontogenetic pattern is present in rats as well. Habituation as well as classical conditioning to tactile stimuli in rats may be elicited on the 19th and 20th gestational days, a few days after the appearance of the response to tactile stimuli. ${ }^{39,40}$ The auditory brainstem response in rats may be first evoked on the 7 th postnatal day. ${ }^{41}$

\section{Anencephaly and neurologic functioning}

Anencephaly is a brain malformation, where the brain stem is hierarchically the highest functional part of the CNS. In a paper published in 1949, there is a description of behavior of a newborn with anencephaly during 85 days of postnatal life. It was proven postmortem that the highest level of CNS was at the level of the thalamus. When the patient's behavior was analyzed, it was registered that if the patient was handled roughly, he cried weakly, and when the investigator coddled him, he showed contentment and settled down in the arms of the investigator. He would sleep after feeding and awaken when hungry. He expressed his hunger by crying. In response to painful stimuli, he withdrew his limbs. He died due to a frontal epidural abscess. ${ }^{42}$ Other studies also described neural function and behavior in anencephalic fetuses. Sweet tastes of sugar elicit positive facial expressions of liking, whereas bitter or salty tastes elicit negative facial expressions of disgust in anencephalic newborns. If the skin of the anencephalic newborn is exposed to stinging, pressure or punching, they cry painfully. ${ }^{43,44}$ Based on neurological examination of anencephalic newborns it is concluded that responses to noxious stimuli such as avoidance, withdrawal, or painful crying are of a brain stem origin in the human species. They also express wake/sleep cycles. ${ }^{45}$ When novel acoustic stimuli were presented, the anencephalic infant showed an orienting response, and cardiac slowing, during the first 
2 months of life. The anencephalic infant also habituated to acoustic stimuli. ${ }^{46}$

\section{Hydranencephaly and neurological functions}

Hydranencephaly is a condition in which the cerebral hemispheres are absent to varying degrees and the defect is filled with the cerebrospinal fluid. Remnants of the cortex cerebri are usually basal and medial parts. Mesodiencephalic structures are usually intact. On autopsy, the remaining cortical tissue shows gliosis, and destruction of corticopetal and corticofugal fibers. ${ }^{47}$ Patients with hydranencephaly, aged between 5 and 17 years old, in spite of being definitely in vegetative state, possess discriminative awareness for objects, music, etc. They can distinguish familiar from unfamiliar people and environments. Hydranencephalic patients also express social interactions, functional vision, appropriate affective responses, and associative learning. Goal-directed behavior could also be observed. ${ }^{48}$ They can feel pain, they can cry, smile, hug and kiss members of their families and caregivers. They anticipate and expect events such as a particular television program or a visit to someone familiar. ${ }^{49}$

\section{Anencephaly, hydranencephaly and the implications for fetal pain}

What implications do the abovementioned behavior of newborns with anencephaly have on the process of the fetus starting to feel pain? Pain contains sensory and affective components. The sensory component is clearly visible in avoidance reactions and withdrawal to noxious stimuli. Crying in response to rough handling shows affective components in interactions with the mother or with medical staff. Showing contentment and settling down as a response to treatment with care or kindness also shows affective components in interaction with other people. Such interaction is necessary for bonding between the mother and the newborn, and the further emotional relationship between mother and infant, and represents one step in the emotional development of the infant. ${ }^{50}$ The presence of the orienting response to a novel stimulus as well as habituation also show the possibility for adequate reactions to environment. If the general definition of perception is taken into account, stating that it includes the organization, identification, and interpretation of sensory information in order to represent and understand the environment, anencephaly demonstrates that the basic, most general, appropriate interaction with the environment can be achieved with a functional brain stem.
Patients with hydranencephaly possess all of the elements necessary for pain registration. They can learn, they show emotional reactions during interaction with people, and they are able to anticipate events. Basically, they fulfill the criteria for pain according to the International Association for the Study of Pain, which defines pain as an unpleasant sensory and emotional experience associated with actual or potential tissue damage.

\section{Development of systems related to nociception and pain in the fetus}

Having said all that, the period in which the fetus experiences pain is the period when sensory nerve endings, sensory receptors, peripheral nerves, the spinal cord, and the structure of the mesodiencephalon show minimal functional maturity in relation to nociception, processing and response. It should be noted that stimulus of any modality can cause pain if sufficient intensity is applied.

The nerve endings of the fifth cranial nerve have reached the basement membrane of the epithelium in the oral cavity at the 8th gestation week and by the 9th gestation week they have reached basement membrane of the face epithelium. ${ }^{51}$ C fibers, which transmit nociception through unmyelinated fibers, make contact with the spinal cord at about 10 gestation weeks. ${ }^{52}$ The Pacinian corpuscles of the finger, which register sudden disturbances in vibration and pressure, begin to develop at about 10-11 gestation weeks. ${ }^{53}$ The crude end disks similar to Merkel's corpuscles in the lips are present at the 12th week of gestation. These corpuscles are transducing information about the low-frequency vibrations $(30-50 \mathrm{~Hz})$ that occur when textured objects are moved across the skin. ${ }^{54}$

Tracts related to the transmission of nociceptive signals to the reticular formation of the brain stem are spinoreticular and spinomesencephalic. Efferent tracts responsible for the brain stem's executive function are vestibulospinal, reticulospinal, and rubrospinal.

Although exact data related to the maturation of spinoreticular, spinomesencephalic, vestibulospinal, reticulospinal, rubrospinal fibers are missing, spinal cord development related to the histological regions and morphology is well explained. Until the 12th week of gestation all parts of spinal cord containing afferent and efferent pathways are present in humans..$^{55}$

Neurotransmitters which relay information about nociception are substance $\mathrm{P}$ and glutamate amino acid. It is reported that substance $\mathrm{P}$ is present in the spinal cord at the early stage of development between the 5 th and 7 th gestation weeks and in the brainstem nuclei between the 11th and 12th 
weeks of gestation. ${ }^{56}$ Glutamate amino acid is also present in this period in the spinal cord, brain stem and thalamus. ${ }^{57}$ The neurotransmitters involved in attenuating nociception are also present in the spinal cord in this period.

Acetylcholinesterase and enkephalin immunoreactivities were detected first in the spinal cord between the 5 th to 7 th gestation weeks, then in the brainstem nuclei between the 11 th and 12th weeks of gestation. Expressions of neuronal nitric oxide synthase were present in the posterior horn of the spinal cord from 2 nd month of gestation. ${ }^{58}$

Immunoreactivity for neuropeptide $\mathrm{Y}$, also involved in attenuating nociception, appeared in the upper segments of the spinal cord at the 12 th gestation week. ${ }^{56}$ Galanin, another neuropeptide involved in pain attenuation was first detected in spinal cord after the 16 th gestation week. ${ }^{59}$ Serotoninergic neurons were found in the dorsal raphe nucleus at the 10th week of gestation. ${ }^{56,60}$

Opioid neuropeptides have a role in the early learning of new associations related to emotion regulation and the impact of touch-based interventions. ${ }^{61}$ Enkephalin was present from the 12th week of gestation at the brain stem. ${ }^{58,62}$ Betaendorphin and beta-lipotropin were present in the cephalic part of embryo starting at the 7 th week of pregnancy. ${ }^{63}$

The centro-median nucleus starts to segregate from the rest of intralaminar nuclei between the 10th and 14th week of gestation. ${ }^{64}$ This group of thalamic nuclei receives nociceptive afferents. They participate in general arousal, affective aspects of pain as well as in the integration of sensory submodalities. $^{4,65}$

Myelination of nerve fibers is absent in the first trimester of gestation in the human species. However, the myelination process should not be critical for pain perception during development. Even in the peripheral nerves of human adults, nociceptive impulses are carried through unmyelinated $\mathrm{C}$ polymodal fibers as part of peripheral nerves. ${ }^{66}$ Also for classical conditioning, the myelination of the CNS is not a necessary condition. Rat fetuses could undergo classical conditioning, while myelination process starts postnataly. ${ }^{67,68}$

\section{Development of neurotransmitters which regulate arousal}

Neurotransmitters related to regulation of arousal are present at the 12 th week of gestation. Serotonin was present from the 10th gestation week in raphe dorsalis nuclei in the brain stem, as has already been suggested. ${ }^{60}$ Granular vesicles in the neuronal bodies of the locus coeruleus containing catecholamine are present at the 11 th gestation week. ${ }^{69}$ Using immunohistochemical method, other authors detected noradrenalin and serotonin in the brain stem, even earlier, at 4-5 gestation weeks. ${ }^{70}$ Acetylcholinesterase was present in the brain stem nuclei and thalamus between the 10th and 12 th gestation week. ${ }^{58,71}$ In the thalamus, the activity of acetylcholinesterase could be detected starting from the 10th week of gestation. The capability for arousal maintains the process of sensory integration and response at the level of the mesodiencephalon.

\section{Functional maturation of the fetal response to touch and stroke}

The reaction to touch begins during the 7 th week of gestation when touching the peri-oral area results in the head turning away. The palms of the hands become sensitive to stroking at the 10 th-11th weeks of gestation. During the 12th gestation week the sensitive area has spread to the chest. The soles of the feet become sensitive around the 13th-14th weeks of gestation. ${ }^{37}$

\section{Neurophysiological maturation of the brain stem}

Basic characteristics of the neuron are excitability and conduction of electrical impulses. Results obtained during cesarean section show that spontaneous, intermittent bursts of electrical activity are present in the brain stem from the 10th week of gestation onward, while as a response to the stretching reflex, it appears from the 12th gestation week onward. ${ }^{72}$ Another study suggested that bursts of fast and slow wave activity in the brain stem appear in the 7 th gestation week. ${ }^{73}$ Excitation of brain stem neurons as a response to the stretching reflex show the development of integrative and regulative activities of the mesodiencephalon lower spinal reflexes.

\section{The fetus is more prone to pain than adults}

Whether the fetus is more prone to pain, and whether it feels it more intensively than newborns, can be indirectly concluded from the published data. Even though, as it has been stated, the structures which participate in pain modulation exist as early as in the period between the 12 th and 14th gestation week, inhibitory descending serotonin pathways in the nociceptive system, which are used to block painful stimuli, mature only after birth. This suggests that the fetus is more sensitive to nociception than infants and may explain why newborns show exaggerated behavioral reaction to sensory provocation. ${ }^{44}$ The mean threshold for the initial response for a cutaneous withdrawal reflex is lower for younger premature infants. At 29 weeks it was $0.237 \mathrm{~g}$, whereas the mean threshold at 41 weeks was $0.980 \mathrm{~g}$. This also suggests that younger 
fetuses are more sensitive to painful stimuli than older ones. ${ }^{74}$ Early painful experience could have various long-lasting effects. Repeated stimulation with von Frey hairs led to a significant lowering of the threshold or "sensitization" of the cutaneous withdrawal reflex in infants from the 27 th gestation week up to the 35 th gestation week. ${ }^{74}$ These data show that repeated painful stimulation could also cause sensitization, and consequently the fetus could be more sensitive to painful stimulus. Newborns are also prone to the long-lasting effects of pain. Neonatal circumcision without application of local anesthetics causes a stronger pain response to subsequent routine vaccination than in uncircumcised infants at 4 and 6 months of age. ${ }^{75}$

Hyperalgesia during development has also been observed in other species as well, such as, for example, the rat. Electrical activation of periaqueductal gray matter does not produce analgesia until the 21 st postnatal day. ${ }^{76}$ Only in the period from the 34th to the 40th postnatal day does the sensitivity to pain appear as it does in adult subjects. ${ }^{77}$

\section{Conclusion}

Taking everything that has been said into account, it can be concluded that an early form of pain may appear from the 15 th week of gestation onward. Bearing in mind the dominant role of the reticular formation of the mesodiencephalon, which is marked by a wide divergence of afferent information, a sense of pain transmitted through it is diffuse and can dominate the overall perception of the fetus. In the later phases of gestation, a pivotal role in the regulation activity of the CNS, including pain perception, are taken over by the structures of the diencephalon and the cortex cerebri. The threshold for tactile stimuli is lower at earlier stages of gestation. The pain inhibition mechanisms are not sufficiently developed during intrauterine development, which is another factor leading to increased intensity of pain in the fetus. All this points to the fact that the fetus is extremely sensitive to painful stimuli, and that this fact should be taken into account when performing invasive medical procedures on the fetus. It is necessary to apply adequate analgesia to prevent the suffering of the fetus.

\section{Acknowledgments}

This article is supported by work from COST Action IS1405 BIRTH (Building Intrapartum Research Through Health) - an interdisciplinary whole system approach to understanding and contextualizing physiological labor and birth.

\section{Disclosure}

The authors report no conflicts of interest in this work.

\section{References}

1. Lowery CL, Hardman MP, Manning N, Whit Hall R, Anand KJS, Clancy B. Neurodevelopmental changes of fetal pain. Semin Perinatol. 2007;31(5):275-282.

2. Merskey H, Lindblom U, Mumford JM, Nathan PW, Sunderland S. Part III: Pain terms, a current list with definitions and notes on usage. In: Merskey H, Bogduk N, editors. Classification of Chronic Pain. 2nd ed. Seattle: IASP Press; 1994:223-229.

3. Mellor DJ, Diesch TJ, Gunn AJ, Bennet L. The importance of "awareness" for understanding fetal pain. Brain Res Rev. 2005;49(3):455-471.

4. Ropper AH, Brown RH. Adams and Victor's Principles of Neurology. 8th ed. New York: The McGraw-Hill Companies Inc; 2005.

5. Derbyshire SWG. Fetal pain: do we know enough to do the right thing? Reprod Health Matters. 2008;16(31):117-126.

6. Brusseau R, Myers L. Developing consciousness: fetal anesthesia and analgesia. Seminars in Anesthesia, Perioperative Medicine and Pain. 2006;25(4):189-195.

7. Glover V. Fisk NM. Fetal pain: implications for research and practice. Br J Obstet Gynaecol. 1999;106(9):881-886.

8. Zecevic N. Verney C. Development of the catecholamine neurons in human embryos and fetuses, with special emphasis on the innervations of the cerebral cortex. J Comp Neurol. 1995;351(4):509-535.

9. Denk F, McMahon SB, Tracey I. Pain vulnerability: a neurobiological perspective. Nature Neurosci. 2014;17(2):192-200.

10. Yoneyama Y, Suzuki S, Sawa R, Kiyokawa Y, Power GG, Araki T. Plasma adenosine levels and P-selectin expression on platelets in preeclampsia. Obstet Gynecol. 2001;97(3):366-370.

11. Donaldson A, Nicolini U, Symes EK, Rodeck CH, Tannirandorn Y. Changes in concentrations of cortisol, dehydroepiandrosterone sulphate and progesterone in fetal and maternal serum during pregnancy. Clin Endocrinol (Oxf). 1991;35(5):447-451.

12. Carl P, Høgskilde S, Nielsen JW, et al. Pregnanolone emulsion. A preliminary pharmacokinetic and pharmacodynamic study of a new intravenous anaesthetic agent. Anaesthesia. 1990;45(3):189-197.

13. Burgess JA, Tawia SA. When did you first begin to feel it? -- locating the beginning of human consciousness. Bioethics. 1996;10(1):1-26.

14. Rogers MC. Do the right thing: pain relief in infants and children. $N$ Engl J Med. 1992;326(1):55-56.

15. Gitau R, Fisk NM, Teixeira JM, Cameron A, Glover V. Fetal hypothalamic-pituitary-adrenal stress responses to invasive procedures are independent of maternal responses. J Clin Endocrinol Metab. 2001;86(1):104-109.

16. Giannakoulopoulos X, Teixeira J, Fisk N, Glover V. Human fetal and maternal noradrenaline responses to invasive procedures. Pediatr Res. 1999;45(4 Pt 1):494-499.

17. Penfield W, Jasper HH. Epilepsy and the functional anatomy of the human brain. Boston MA: Little, Brown \& Co; 1954.

18. Schiff ND. Central thalamic contributions to arousal regulation and neurological disorders of consciousness. Ann NY Acad Sci. 2008;1129:105-118.

19. Anand KJS, Clancy B. Fetal pain? Pain. Clinical updates. 2006;14(2):1-4.

20. Berntson GG. Organization of brainstem behavioral systems. Brain Res Bull. 1976;1(5):471-483.

21. Woods JW. Behavior of chronic decebrate rats. J Neurophysiol. 1964;27(4):635-644.

22. Bignall KE, Schramm L. Behavior of chronically decerebrated kittens. Exp Neurol. 1974;42(3):519-531.

23. Bucheald JS. Brainstem substrates of sensory information processing and adaptive behavior. UCLA Forum Med Sci. 1975;18:315-333.

24. Whishaw IQ, Schallert T, Kolb B. An analysis of feeding and sensorimotor abilities of rats after decortication. J Comp Physiol Psychol. 1981 Feb;(1):85-103.

25. Panksepp J, Normansell L, Cox JF, Siviy SM. Effects of neonatal decortication on the social play of juvenile rats. Physiol Behav. 1994;56(3):429-443.

26. Swithers-Mulvey SE, Mishu KR, Hall WG. Oral habituation in rat pups is in the brainstem. Physiol Behav. 1992;51(3):639-642. 
27. Ronca AE, Berntson GG, Tuber DS. Cardiac orienting and habituation to auditory and vibrotactile stimuli in the infant decerebrate rat. Dev Psychobiol. 1985;18(6):545-558.

28. Norman RJ, Buchwald JS, Villablanca JR. Classical conditioning with auditory discrimination of the eye blink in decerebrate cats. Science. 1977;196(4289):551-553.

29. Rasmussen A, Zucca R, Jirenhend DA, Johansson F, Ortenblad C, Svensson P, Hesslow G. Golgi cell activity during eyeblink conditioning in decerebrate ferrets. Cerebellum. 2014;13(1):42-45.

30. Kelly TM, Zuo CC, Bloedel JR. Classical conditioning of the eyeblink reflex in the decerebrate-decerebellate rabbit. Behav Brain Res. 1990;38(1):7-18.

31. Klosterhalfen W, Klosterhalfen S. Habituation of heart rate in functionally decorticate rats. Behav Neurosci. 1985;99(3):555-563.

32. Amiel-Tison C. Clinical assessment of the infant nervous system. In: Levene MI, Lilford RJ, editors. Fetal and neonatal neurology and neurosurgery (2 ${ }^{\text {nd }}$ edition). Edinburgh: Churchill Livingstone; 1995:83-104

33. Gottlieb G. Introduction to behavioral embryology. In: Gottlieb G, editor. Studies on the Development of behavior and the Nervous System. Behavioral Embryology New York: Academic; 1973;1:3-45.

34. Berntson GG, Tuber DS, Ronca AE, Bachman DS. The decerebrate human: associative learning. Exp Neurol. 1983;81(1):77-88.

35. Leader LR, Baillie P, Martin B, Vermeulen E. The assessment and significance of habituation to a repeated stimulus by the human fetus Early Hum Dev. 1982;7(3):211-219.

36. Birnholz JC, Benacerraf BR. The development of human fetal hearing. Science. 1983;222(4623):516-518.

37. Humphrey T. Postnatal repetition of human prenatal activity sequences with some suggestions on their neuroanatomical basis. In: Robinson RJ editor. Brain and early behavior. London: Academic Press; 1969:43-71.

38. Sohmer H, Freeman S. Functional development of auditory sensitivity in the fetus and neonate. J Basic Clin Physiol Pharmacol. 1995;6(2): 95-108.

39. Smotherman WP, Robinson SR. Behaviour of rat fetuses following chemical or tactile stimulation. Behav Neurosci. 1988;102(1):24-34.

40. Varlinskaya EI, Petrov ES, Simonik DK, \& Smotherman WP. Classical conditioning in the fetal rat with a long delay between presentation of CS and US. Dev Psychobiol. 1997;30(1):49-59.

41. Geal-Dor M, Freeman S, Li G, Sohmer H. Development of hearing in neonatal rats: air and bone conducted ABR thresholds. Hear Res. 1993;69(1-2):236-242.

42. Nielsen JM, Sedgwick RP. Instincts and emotions in an anencephalic monster. J Nerv Ment Dis. 1949;110(5):387-394.

43. Steiner JE. The gustofacial response: observation on normal and anencephalic newborn infants. Symp Oral Sens Percept. 1973;4:254-278.

44. Andre-Thomas. The normal newborn and the anencephalus: reflexes, reactivity and automatism. Presse Med. 1954;62(42):885-886.

45. The Medical Task Force on Anencephaly. The infant with anencephaly. The Medical Task Force on Anencephaly. N Engl J Med. 1990;322(10) 669-674.

46. Graham FK, Leavitt LA, Strock BD, Brown JW. Precocius cardiac orienting in a human anencephalic infant. Science. 1978;199(4326):322-324.

47. Marín-Padilla M. Developmental neuropathology and impact of perinatal brain damage. II: white matter lesions of the neocortex. J Neuropathol Exp Neuro.l 1997;56(3):219-235.

48. Shewmon DA, Holmes GL, Byrne PA. Consciousness in congenitally decorticate children: developmental vegetative state as self-fulfilling prophecy. Dev Med Child Neurol. 1999;41(6):364-374.

49. Aleman B, Merker B. Consciousness without cortex: a hydranencephaly family survey. Acta Paediatr. 2014;103(10):1057-1065.

50. Flacking R, Lehtonen L, Thomson G, et al. Closeness and separation in neonatal intensive care. Acta Paediatr. 2012;101(10):1032-1037.

51. Humphrey T. The development of trigeminal nerve fibers to the oral mucosa compared with their development to cutaneous surfaces. J Comp Neurol. 1966;126(1):91-108.

52. Fitzerald M. Development of pain pathways and mechanism. In: Anand KIS, McGrath PJ, editors. Pain Research and Clinical management. Pain in Neonates. Amsterdam: Elsevier; 1993;5:19-38
53. Cauna N, Mannan G. Development and postnatal changes of digital Pacinian corpuscles (corpuscula lamellosa) in the human hand. $J$ Anatom. 1959;93(Pt 3):271-286.

54. Hoog ID. Sensory nerves and associated structures in the skin of human fetuses of 8 to 14 weeks of menstrual age correlated with functional capability. J Comp Neurol. 1941;75(3):371-410.

55. Altman J, Bayer SA. Development of the human spinal cord. New York: Oxford University Press; 2001.

56. Yew DT, Chan WY. Early appearance of acetylcholinergic, serotoninergic, and peptidergic neurons and fibers in the developing human central nervous system. Microsc Res Tech. 1999;45(6):389-400.

57. Datta SC, Mukherjee KL. Changes in free amino acid levels in developing humanfoetal brain regions. J Neurochem. 1983;40(4):1150-1154.

58. Zhang Y, Liu XH. [Expression of nNOS, Pax 3 and $\mathrm{Cx} 43$ proteins in early developing posterior horn of embryonic and fetal human spinal cord] Nan Fang Yi Ke Da Xue Xue Bao. 2009;29(8):1651-1653. Chinese.

59. Suburo AM, Gu XH, Moscoso G, Ross A, Terenghi G, Polak JM. Developmental pattern and distribution of nerve growth factor low-affinity receptor immunoreactivity in human spinal cord and dorsal root ganglia: comparison with synaptophysin, neurofilament and neuropeptide immunoreactivities. Neuroscience. 1992;50(2):467-482.

60. Shen WZ, Luo ZB, Zheng DR, Yew DT. Immunohistochemical studies on the development of 5-HT (serotonin) neurons in the nuclei of the reticular formation of human fetuses. Pediatr Neurosci. 1989;15(6):291-295.

61. Weller A, Feldman R. Emotion regulation and touch in infants: the role of cholecystokinin and opioids. Peptides. 2003;24(5):779-788.

62. Yew DT, Luo CB, Shen WZ. Immunohistochemical localization of enkephalin and substance $\mathrm{P}$ in the nucleus caudalis of the spinal trigeminal $\mathrm{V}$ in the medulla oblongata of the human fetus. Neuroscience. 1992;51(1):185-190.

63. Facchinetti F, Storchi AR, Petraglia F, Garuti G, Genazzani AR. Ontogeny of pituitary beta-endorphin and related peptides in the human embryo and fetus. Am J Obstet Gynecol. 1987;156(3):735-739.

64. Mojsilovic J, Zečevic N. Early development of the human thalamus. Golgi and Nissl study. Early Hum Dev. 1991;27(1-2):119-144.

65. Kandel Er, Schwartz JH, Jessell TM, Siegelbaum SA, Hudspeth AJ. Priciples of Neural Sciences. 5th ed. New York: The McGraw-Hill Companies Inc; 2013.

66. Anand KJS, Phil D, Hickey PR. Pain and its effects in the human neonate and fetus. N Engl J Med. 1987;317(21):1321-1329.

67. Smotherman WP. Classical conditioning in the rat fetus. III. Retention, extinction, and re-activation of the conditioned response (CR). Dev Psychobiol. 2003;42(2):181-193.

68. Tessitore C, Brunjes PC. A comparative study of myelination in precocial and altricial murid rodents. Dev Brain Res. 1988;43(1):139-147.

69. Choi BH, Antanitus DS, Lapham LW. Fluorescence histochemical and ultrastructural studies of locus coeruleus of human fetal brain. $J$ Neuropathol Exp Neurol. 1975;34(6):507-516.

70. Sudström E, Kölare S, Souverbie F, et al. Neurochemical differentiation of human bulbospinal monoaminergic neurons during the first trimester. Brain Res Dev Brain Res. 1993;75(1):1-12.

71. Chernyshevskaia IA. The characteristics of cholinesterase distribution in the development of the human and mammalian brains. Zh Evol Biokhim Fiziol. 1991;27(4):459-466.

72. Bergström RM, Bergström L. Prenatal development of stretch reflex fuctions and brain stem activity in the human. Ann Chir Gynaecol Fenn Suppl. 1963;52(117):1-21.

73. Borkowski WJ, Bernstine RL. Electroencephalography of the fetus. Neurology. 1955;5(5):362-365.

74. Andrews K, Fitzgerald M. The cutaneous withdrawal reflex in human neonates: sensitization, receptive fields, and the effects of contralateral stimulation. Pain. 1994;56(1):95-101.

75. Taddio A, Katz J, Ilersich AL, Koren G. Effect of neonatal circumcision on pain response during subsequent routine vaccination. Lancet. 1997;349(9052):599-603.

76. van Praag H, Frenk H. The development of stimulation-produced analgesia (SPA) in the rat. Brain Res Dev Brain Res. (1991);64(1-2):71-76.

77. Jiang MC, Gebhart GF. Development of mustard oil-induced hyperalgesia in rats. Pain. 1998;77(3):305-313. 
The Journal of Pain Research is an international, peer reviewed, open access, online journal that welcomes laboratory and clinical findings in the fields of pain research and the prevention and management of pain. Original research, reviews, symposium reports, hypothesis formation and commentaries are all considered for publication.
The manuscript management system is completely online and includes a very quick and fair peer-review system, which is all easy to use. Visit http://www.dovepress.com/testimonials.php to read real quotes from published authors. 